\title{
The added value of bedside examination and screening QST to improve neuropathic pain identification in patients with chronic pain
}

This article was published in the following Dove Press journal: Journal of Pain Research

\author{
Hans Timmerman' \\ Oliver HG Wilder-Smith ${ }^{1,2}$ \\ Monique AH Steegers ${ }^{3}$ \\ Kris CP Vissers ${ }^{3}$ \\ André PWolff ${ }^{4}$ \\ 'Department of Anesthesiology, Pain \\ and Palliative Medicine, Radboud \\ University Medical Center, Nijmegen, \\ the Netherlands; ${ }^{2}$ Center for Sensory- \\ Motor Interaction, Aalborg University, \\ Aalborg, Denmark; ${ }^{3}$ Department of \\ Anesthesiology, Pain and Palliative \\ Medicine, Radboud University Medical \\ Center, Nijmegen, the Netherlands; \\ ${ }^{4}$ Department of Anesthesiology, Pain \\ Center, University of Groningen, \\ University Medical Center Groningen, \\ Groningen, the Netherlands
}

Correspondence: Hans Timmerman Department of Anesthesiology, Pain and Palliative Medicine, Radboud University Medical Center, PO Box 9101 , Huispost 549 , Nijmegen $6500 \mathrm{HB}$, the Netherlands Tel +3। 243655755

Fax $+3|2436| 6985$

Email hans.timmerman@radboudumc.nl
Background: The assessment of a neuropathic pain component (NePC) to establish the neurological criteria required to comply with the clinical description is based on history taking, clinical examination, and quantitative sensory testing (QST) and includes bedside examination (BSE). The objective of this study was to assess the potential association between the clinically diagnosed presence or absence of an NePC, BSE, and the Nijmegen-Aalborg screening QST (NASQ) paradigm in patients with chronic ( $\geq 3$ months) low back and leg pain or with neck shoulder arm pain or in patients with chronic pain due to suspected peripheral nerve damage.

Methods: A total of 291 patients participated in the study. Pain (absence or presence of neuropathic pain) was assessed independently by two physicians and compared with BSE (measurements of touch [finger, brush], heat, cold, pricking [safety pin, von Frey hair], and vibration). The NASQ paradigm (pressure algometry, electrical pain thresholds, and conditioned pain modulation) was assessed in 58 patients to generate new insights.

Results: BSE revealed a low association of differences between patients with either absent or present NePC: heat, cold, and pricking sensations with a von Frey hair were statistically significantly less common in patients with present NePC. NASQ did not reveal any differences between patients with and without an NePC.

Conclusion: Currently, a standardized BSE appears to be more useful than the NASQ paradigm when distinguishing between patients with and without an NePC.

Keywords: quantitative sensory testing, NASQ, Nijmegen-Aalborg screening QST, clinical assessment, diagnostic accuracy

\section{Introduction}

Neuropathic pain is defined by the International Association for the Study of Pain (IASP) as "pain caused by a lesion or disease of the somatosensory nervous system". It is a clinical description rather than a clinical diagnosis which would require "a demonstrable lesion or disease that satisfies the established neurological diagnostic criteria". ${ }^{1}$ In the general population, $6 \%-8 \%$ suffer from neuropathic pain. ${ }^{2-4}$ Nociceptive pain is defined as "pain that arises from actual or threatened damage to non-neural tissue and is due to activation of nociceptors". This allows us to distinguish between patients with neuropathic pain (classification based on an abnormally functioning somatosensory nervous system) and nociceptive pain (classification based on a normally functioning somatosensory nervous system). Because co-existence of both conditions (mixedpain condition) is frequently observed in daily clinical practice, La Cesa et al suggest using the presence or absence of a neuropathic pain component (absent or present 
NePC). ${ }^{5} \mathrm{NePC}$ assessment is based on history taking, clinical examination, and (quantitative) sensory testing and includes bedside examination (BSE). ${ }^{6-8}$ Clinical examination alone can never offer proof that a specific pain is of neuropathic origin, but it provides supporting evidence for alterations in the functioning of the nervous system. ${ }^{6}$ According to the IASP neuropathic pain special interest group (NeuPSIG), abnormal sensory findings should be neuroanatomically plausible when an NePC is present, and the sensory signs should be associated with the neuroanatomically plausible distribution compatible with an underlying relevant lesion or disease of the somatosensory nervous system. ${ }^{9,10}$ As part of a bedside clinical neurological examination, sensory testing can identify negative sensory symptoms such as hyperalgesia or hypoesthesia and/or positive sensory symptoms such as allodynia and hyperalgesia. ${ }^{5}$ According to Haanpää et al, ${ }^{6}$ BSE can possibly identify where the pathology causing the pain can be found in the central nervous system.

In the last decades, quantitative sensory testing (QST) has complemented traditional neurological BSE tests. QST uses psychophysical tests defined as stimuli with predetermined physical properties based on specific measurement protocols for the analysis of somatosensory aberrations. ${ }^{11-13}$ QST measures responses to sensory stimuli and can be used to assess somatosensory system function, ${ }^{11,12}$ the measurement of the altered peripheral and/or central pain sensitivity, ${ }^{14-16}$ and descending pain modulation. ${ }^{17,18}$ QST is thought to offer greater precision and reliability when assessing somatosensory system functionality than a standard $\mathrm{BSE}^{19,20}$ because of the use of controlled automated devices. There is evidence that QST improves the diagnostic process of patients with pain, and that it may be valuable when monitoring for a specific anti-neuropathic treatment. ${ }^{21,22}$ Moreover, an altered pain modulation can be assessed on the basis of signs and symptoms of peripheral and central sensitization ${ }^{17,23-25}$ and by the use of conditioned pain modulation (CPM). ${ }^{19,26} \mathrm{CPM}$ is a physiological phenomenon that can be used to assess the quality of the endogenous pain inhibitory pathway, also known as the "pain inhibits pain" phenomena. ${ }^{27}$ The Nijmegen-Aalborg screening QST (NASQ) ${ }^{15,16,24,28}$ measures pain and central pain processing under standardized conditions using defined stimuli and experienced intensity ratings. There is no "gold standard" for the diagnosis of NePC, and the association between NePC and BSE/NASQ has not yet been fully evaluated. There is a need for studies to more objectively identify the presence of an NePC and to assess the diagnostic accuracy of BSE and NASQ for NePC. ${ }^{5}$
The objective of this study was to assess the potential association between clinically diagnosed absent or present NePC and BSE and NASQ in patients with chronic $(\geq 3$ months) low back and leg pain (LBLP) or with neck shoulder arm pain (NSAP) radiating into the $\operatorname{leg}(\mathrm{s})$ or $\operatorname{arm}(\mathrm{s})$, or in patients with chronic pain due to suspected peripheral nerve damage (sPND).

\section{Methods}

This study is based on a cross-sectional, observational research design to generate new insights into the clinical assessment of NePC. It is a sub-analysis of a study approved by the medical and ethical review board Committee on Research Involving Human Subjects, region Arnhem-Nijmegen, Nijmegen, the Netherlands, dossier number: 2008/348; NL 25343.091.08.

In the original study conducted between October 2009 and June 2013, we validated the Dutch PainDETECT ${ }^{29}$ and the DN4. ${ }^{30,31}$ The PainDETECT ${ }^{32}$ and the DN4 ${ }^{33}$ were both developed to screen for the presence of neuropathic pain. The patient self-administered PainDETECT is a simple screening tool with no need for physical examination. The instrument consists of one item about the pain course pattern, one about radiating pain, and seven questions about the gradation of pain. The clinician-administered DN4 consists of a total of 10 items with yes/no answers. It is divided into two questions (symptoms) and two physical examination tests (signs). The two sign items were incorporated in the sensory examination part of the standardized assessment form. ${ }^{28}$ The protocol was registered in the Dutch National Trial Register: NTR 3030 and published by Timmerman et al. ${ }^{28}$ Patients provided written informed consent after screening, but before participation in the study.

\section{Participants}

We recruited patients as part of the Dutch validation studies concerning the PainDETECT and the DN4. Inclusion criteria were male and female adult patients aged over 18 years with chronic ( $\geq 3$ months) LBLP or NSAP, or patients with chronic pain due to SPND. We excluded patients suspected for or diagnosed with malignancy; compression fractures; patients with diffuse pains such as fibromyalgia or ankylosing spondylitis; severe mental illness; chronic alcoholism or substance abuse; inability to fill in the questionnaire adequately; or incapable of understanding the Dutch language.

\section{Pain classification}

Classification of patients' pain was based on the NeuPSIG guidelines on neuropathic pain assessment. ${ }^{6}$ Pain classification was performed consecutively but blinded for the outcome 
on the same patient independently by two physicians working in different compositions, and then categorized into three groups: "absent NePC", "present NePC" where both physicians were in agreement, or "undetermined NePC" in cases where they did not agree. A full medical history and clinical examination including sensory BSE was taken ${ }^{6,7,21,28,34}$ and considered as the gold standard for NePC diagnosis.

\section{Bedside examination}

Multicenter recruitment took place in the Netherlands in three academic pain centers and in four non-academic pain centers. A standardized $\mathrm{BSE}^{28}$ was independently performed by two physicians during the validation study for the two neuropathic pain screening tools. Prior to the study, the physicians were trained in the standardized evaluation of patients with chronic pain using specific modalities such as touch, pin prick, pressure, cold, heat, vibration, and temporal summation. The location indicated by the patient as having maximum pain was compared with the mirrored location on the contralateral side. When the pain had a double-sided character, a location without pain but as close as possible to the original mirror site was tested for comparison. Patients were asked the following: 1) is a sensation present? 2) is the sensation unpleasant? or 3 ) is the sensation painful? (all scored as yes, no, or unclear) The outcome was noted by the physician on the standardized assessment form. ${ }^{28}$ The following tests were performed consecutively on each patient independently by two physicians: 1) mechanical static allodynia via blunt pressure with a finger at a force that normally does not evoke pain; 2) dynamic mechanical allodynia via stroking the skin with a Soft Brush (SENSElab ${ }^{\mathrm{TM}}$, Brush-05, Somedic AB, Hörby, Sweden), 2a) one movement of 1-2 centimeter and 2b) three movements of 1-2 centimeters (wind-up response); 3) mechanical pinprick allodynia via touch of the skin with 3a) a plastic safety pin and 3b) a Von Frey hair (TOUCH TEST $\AA^{2}, 5.07,10.0$ g, North Coast Medical Inc., Gilroy, CA, USA); 4) heat allodynia by use of TipTherm ${ }^{\circledR}$ (TipTherm, Brüggen, Germany) in a baby-bottle warmer (ISI mini Baby Bottle Warmer, Assen, the Netherlands) set at 45 degrees Celsius; 5) cold allodynia with an ice cube placed on the skin for 2 seconds; and 6) vibration with a tuning fork (128 $\mathrm{Hz}$; Medipharchem, Wormerveer, the Netherlands) applied to joint, bone, or soft tissue in the region of the pain.

\section{Nijmegen-Aalborg screening QST}

Patients for the additional NASQ part of the study were recruited in one academic pain center and two non-academic pain centers. After screening in the clinical department, patients were asked to participate. The NASQ was performed in a random sub-sample of $20 \%$ of the patient population (LBLP, NSAP, and sPND) by a trained and experienced researcher (HT). ${ }^{28}$ The NASQ paradigm ${ }^{15,16,24,28}$ was used as screening protocol. The NASQ screens for changes in pain processing based on a systematic mechanism-oriented approach. ${ }^{16}$ It maps pain sensitivity at multiple sites by measuring the responses (ie, painful sensations) evoked by mechanical and electrical non-invasive stimuli, and measures the patient's capacity to modulate pain using the CPM. Instructions were standardized and read to each patient from an instruction sheet.

\section{Pressure pain threshold (PPT) test}

A pressure algometer (Somedic AB) was used to measure PPTs bilaterally at each location, expressed in kilo Pascal: thenar (middle part), musculus trapezius pars median (middle part), musculus rectus femoris (15 cm above patella), and musculus abductor hallucis (middle part). In addition to the analysis with an average value over these eight measurement points, we performed additional analyses in the four central measurement points: musculus trapezius pars median (both sides) and musculus rectus femoral (both sides), and the four peripheral measurement points: thenar (both sides) and $\mathrm{m}$. abductor hallucis (both sides).

\section{Electrical pain thresholds}

The QST-3 device (JNI Biomedical ApS, Klarup, Denmark) was used to measure electrical pain thresholds (EPTs) on the left and right body side. Measurement locations were the musculus trapezius pars median (middle part) and the musculus rectus femoris ( $20 \mathrm{~cm}$ above patella). Thresholds were assessed and expressed in milli-Ampère. EPTs were measured as electrical pain detection threshold (EPDT) when the current started to feel pain, and as electrical pain tolerance threshold (EPTT) when the current was as high as the patient could tolerate.

\section{CPM response}

We assessed $\mathrm{CPM}^{17,27}$ via the PPT (CPMp) and the EPT (CPMe) on the $\mathrm{m}$. rectus femoris contralateral to the dominant hand. The noxious stimulus (conditioning stimulation) was to immerse the dominant hand to the wrist in a bucket filled with water and ice cubes (ice water bucket [IWB] test). ${ }^{25}$ The patient was instructed to "keep the hand in the water for as long as possible, until the moment that the sensation becomes unbearable and you want to stop directly". Pain was recorded every 10 seconds on the numeric rating scale. The duration 
of the immersion (with a maximum of 180 seconds) was recorded and the pain intensity at the end of the immersion was also registered. The PPT and the EPT were then assessed again on the contralateral $\mathrm{m}$. rectus femoris. The response was calculated by subtracting the outcome of the pre-measurement from the outcome of the post-measurement. The CPM values were calculated using the following formulas:

$$
\begin{aligned}
& C P M p=\left(\left[P P T_{\text {post }}-P P T_{\text {pre }}\right] / P P T_{\text {pre }}\right) * 100 \\
& C P M e=\left(\left[E P T_{\text {post }}-E P T_{\text {pre }}\right] / E P T_{\text {pre }}\right) * 100
\end{aligned}
$$

CPM was regarded as "positive" when the outcome of the calculation was equal or higher than zero and negative when it was below zero.

\section{Data}

All data were collected on paper from the patients and the physicians and stored at Radboudumc, Nijmegen, the Netherlands. Data management and monitoring were performed using MACRO (MACRO, version 4.1.1.3720, InferMed, London, UK). Data analysis and statistics were performed using Statistical Package for the Social Sciences (SPSS version 20.0, SPSS Inc., Chicago, IL, USA).

\section{Statistical methods}

Qualitative variables are presented as frequencies and percentages. Quantitative variables are presented as mean and $\mathrm{SD}$ or as median and interquartile range. The chi-square test was used to test for significant differences between nominal outcome data. Cramér's $V$ was used as a measure of association between two nominal variables, giving a value between 0 and 1. Mann-Whitney $U$-test was used to test the differences between present and absent NePC. Kruskal-Wallis test was used to study differences between the three (absent NePC, present NePC, and undetermined) groups. We used Cohen's Kappa and the percentage of pair wise agreement to determine the agreement between the BSE between the patient's first and second assessment. A two-tailed $p$-value below 0.05 was considered statistically significant.

\section{Results}

In total, 330 patients with chronic LBLP, NSAP, or sPND were assessed for eligibility. Two patients did not provide informed consent prior to inclusion in the study. Thirty-seven patients were excluded because of not meeting the inclusion and exclusion criteria $(n=13)$; not returning the baseline questionnaires $(n=16)$, and missing pain classification by one physician $(n=5)$ or both physicians $(n=3)$.
BSE was performed in this study in 291 patients by 62 different physicians from seven hospitals. The present NePC group $(n=170)$ consisted of 75 patients with LBLP, 23 patients with NSAP, and 72 patients with sPND. The absent NePC group $(n=58)$ consisted of 28 patients with LBLP, 18 patients with NSAP, and 12 patients with sPND. For the undetermined group ( $\mathrm{n}=63$ ), the numbers were 29,10 , and 24 , respectively (see Figure 1 and Table 1).

The NASQ was performed in a total of 69 patients. Patients were excluded after the NASQ measurements were made: not fulfilling the inclusion and exclusion criteria $(n=9)$ or a missing assessment by a second physician $(n=2)$. Finally, a total of 58 patients (56 Dutch natives, 1 German native, and 1 of Chinese/Indonesian origin) were included in the analysis: 25 with LBLP, 25 with NSAP, and 8 with sPND. After NePC assessment by the physicians, 16 patients were classified as absent NePC, 29 with present NePC, and 13 patients with an undetermined outcome. The absent NePC group, present NePC group, and undetermined group had 4, 14, and 7 patients with LBLP; 12, 7, and 5 patients with NSAP; and 0,7 , and 1 patient(s) with sPND, respectively (see Figure 1 and Table 1).

In Tables 2 and $\mathrm{S} 1$, we have shown the outcome of the $\mathrm{BSE}$ based on the inter-physician agreement on the existence of an NePC. In the first assessment by the physician, the answers on the question "is there a sensation (yes, no, unclear) during testing for heat, cold, touch (brush 3 times), and pricking (both safety pin and von Frey hair)" were significantly lower $(p<0.05)$ for yes in the group with present $\mathrm{NePC}$ compared to the absent NePC group. In the second assessment, the scores for the question "is there a sensation (yes, no, unclear) of heat, cold, touch, (only brush 1 time), and pricking (von Frey hair only)" were significantly lower $(p<0.05)$ for yes in the group with present NePC with a lower percentage of "yes" compared to the absent NePC. The scores for the questions "is the touch with a finger unpleasant?" and "is touch with a brush unpleasant?" were higher for the second assessment for the group with present NePC ( $p=0.049$ and $p=0.006$, respectively). "Painful for touch with a finger" was more common in patients with present $\mathrm{NePC}(p=0.026)$ in the second assessment. "Wind-up" was more common in patients with present NePC compared to the patients with absent NePC (first assessment $p=0.056$; second assessment $p=0.029)$. In Table $\mathrm{S} 1$, we have shown the outcome of the $\mathrm{BSE}$ based on the inter-physician agreement for the occurrence of NePC for patients with LBLP, NSAP, and sPND.

The outcomes of the NASQ measurements related to physician agreement for the existence of $\mathrm{NePC}$ are presented in 


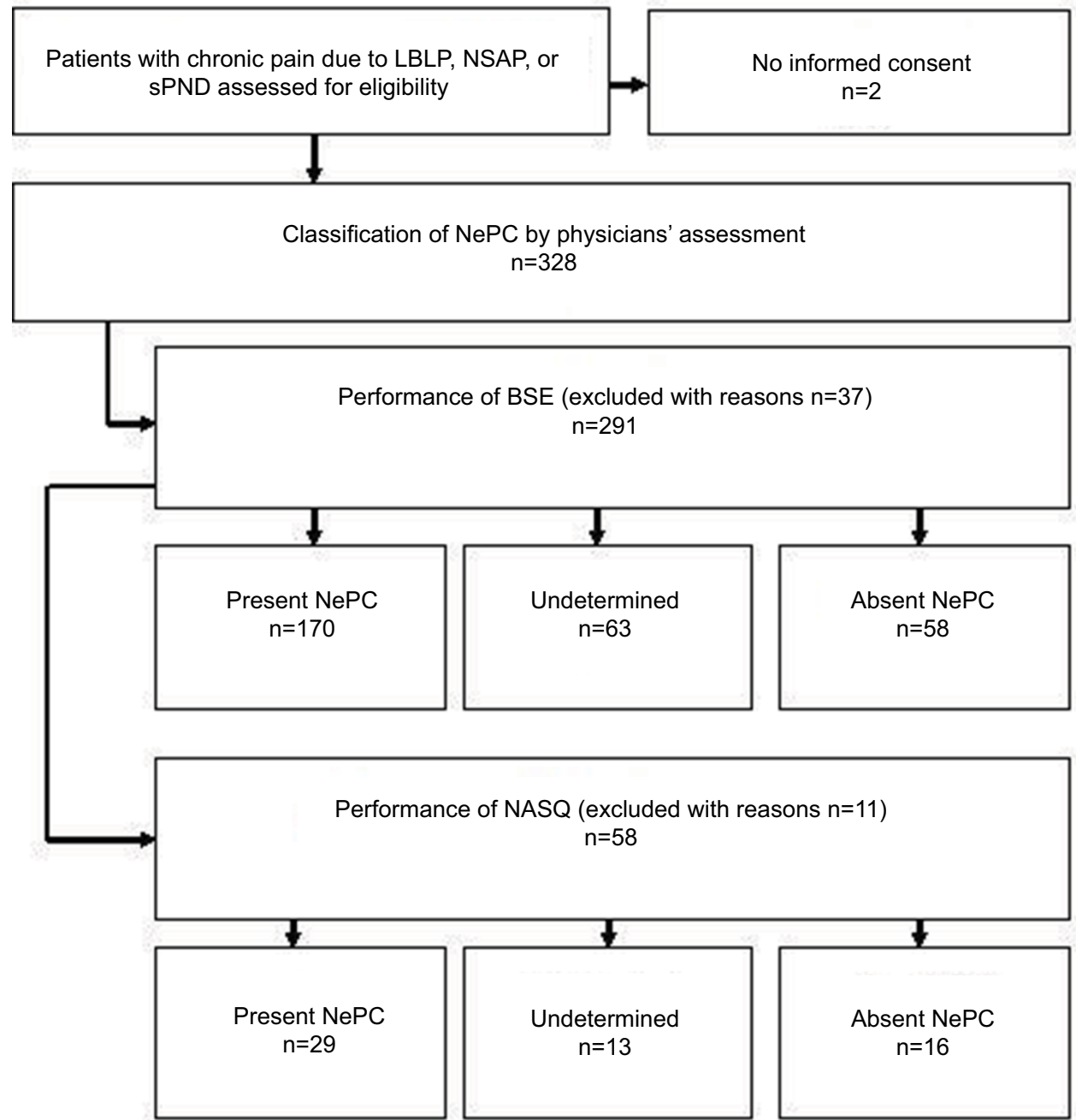

Figure I Flow diagram for the performance of the BSE and NASQ in patients with chronic pain with respect to the physicians' assessment.

Notes: n, number of patients in analysis; Present NePC, NePC is present; Undetermined, both physicians disagree with each other about the presence of a NePC; Absent $\mathrm{NePC}$, no NePC is present.

Abbreviations: LBLP, low back and leg pain; NSAP, neck shoulder arm pain; sPND, suspected peripheral nerve damage; BSE, bedside examination; NePC, neuropathic pain component; NASQ, Nijmegen- Aalborg screening quantitative sensory testing.

Table 3. No significant difference was detected for pressure, EPDT, EPTT, and duration of submerging the hand in the IWB between the absent, present, and undetermined NePC groups. We found no congruency between the CPMp and the CPMe. When basing the CPM classification on pressure values, the significance disappeared for the outcome of the CPM test based on electricity values (response $p=0.440$, CPM-value $p=0.374)$. This was also true when the CPM electricity test outcome was used to analyze the response and CPM value for pressure $(p=0.728$ and $p=0.810$, respectively). Moreover, in the IWB test, we found no significant differences regarding the duration (latency) of submerging the hand between the positive and negative CPM test for both the pressure and electricity conditions $(p=0.120$ and $p=0.711$, respectively).

\section{Discussion}

The aim of this study was to assess the potential association between a clinically diagnosed absent or present NePC, BSE, and NASQ in patients with chronic pain. BSE revealed minor differences, with a low association between patients with present $\mathrm{NePC}$ and patients with absent $\mathrm{NePC}$ following independent clinical NePC assessment by two independent physicians, while none were found with NASQ.

\section{Bedside examination}

We used BSE based on mechanical and thermal testing procedures, performed by two physicians independently and blinded for the results of the other. ${ }^{28}$ The added value of BSE is that it gives insights into the pathology and the localization of the nerve lesion or disease causing the pain. ${ }^{6,7,35,36}$ 
Table I Sociodemographic characteristics for the patients included in the BSE and the NASQ examination related to the physicians' agreement for the existence of an NePC

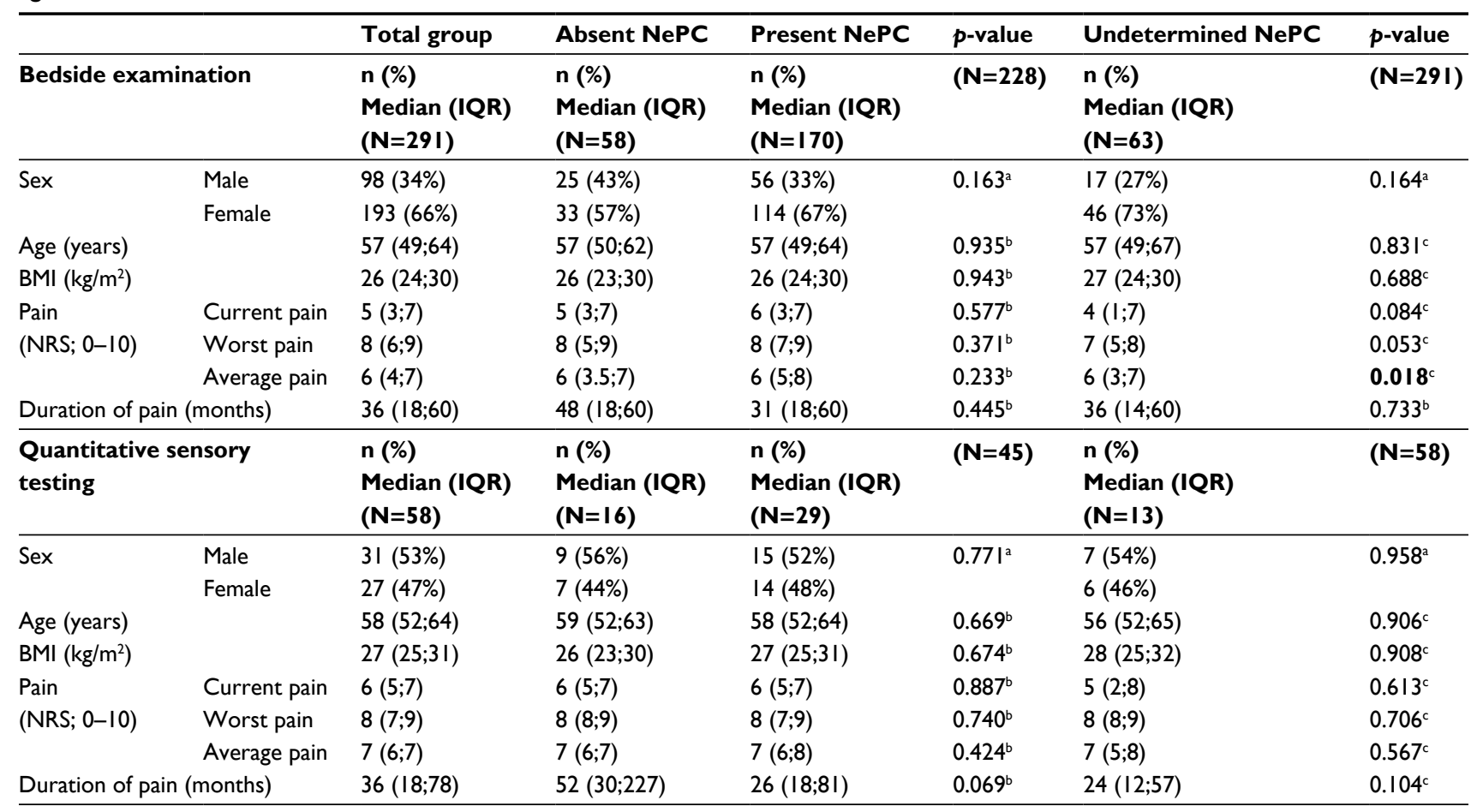

Notes: Classification for the existence of NePC is based on physicians' assessment of the patients. Absent NePC, no NePC is present; Present NePC, NePC is present; $p$-value, value for significant difference between groups ( $p \leq 0.05)$; $\mathrm{N}$, total number of patients in analysis; ${ }^{a}$ chi-square test; ${ }^{b}$ Mann-Whitney $U$-test; ${ }^{\circ} \mathrm{Kruskal}-\mathrm{W}$ allis test. Bold values are statistically significant $(p \leq 0.05)$.

Abbreviations: BSE, bedside examination; NASQ, Nijmegen-Aalborg screening quantitative sensory testing; NePC, neuropathic pain component; BMI, body mass index; NRS, numeric rating scale; median (IQR), median with interquartile range (25\%-75\%).

The BSE results showed statistical significant differences between patients with absent NePC and patients with present NePC. BSE revealed that the sensation of heat, cold, wind-up response (with a brush, three times), pricking with a safety pin, and pricking with a von Frey hair was less common in patients with a present NePC than in those with an absent NePC. In addition, wind-up response occurred more often in patients with present NePC than in those with absent NePC.

\section{Screening QST}

We used the NASQ to assess the altered pain processing, including changes in function of endogenous pain modulation as a secondary test battery. ${ }^{15,28}$ The NASQ test protocol has standardized instructions, an important prerequisite to ensure reliability of the measurements. ${ }^{20,37}$ We found no differences between patients with absent and present NePC regarding PPTs, electrical pain (tolerance) thresholds, and CPM outcomes (number of positive and negative CPM outcomes, the response, the CPM value, and the latency times when submerging the hand in ice water). Granovsky ${ }^{38}$ reported that patients with chronic neuropathic pain express a less efficient (negative) CPM. In our study, we could not confirm this when comparing patients with LBLP, NSAP, or sPND with and without NePC. As suggested by Graven-Nielsen and Arendt-Nielsen, ${ }^{39}$ lower PPTs may be indicative for central sensitization. We also could not find any differences in the pain thresholds of patients with and without NePC. Moreover, a difference in CPM may also suggest a central dysfunction. However, based on our results, we cannot state that there are signs of central sensitization or altered central pain processing as might be suspected because of lower pain thresholds for pressure pain or an impaired CPM, because we did not include age, sex, and education matched controls, which would be necessary to draw these higher level conclusions.

\section{Limitations}

We would have preferred to use the German Research Network on Neuropathic Pain (DFNS) $)^{11,12}$ to BSE because of the standardization of the complete test procedure (written test instructions, application of the test stimuli, and data analyses). ${ }^{12,40}$ However, due to time constraints in a patient care setting, it was not possible and preferable to use such a research test battery. Moreover, in simulating daily clinical practice, fulfilling the DFNS protocol is not applicable due 
Table 2 Bedside examination outcome based on inter-physician (A-B) agreement on the presence of an NePC

\begin{tabular}{|c|c|c|c|c|c|c|c|c|c|c|c|c|c|c|c|c|}
\hline & \multicolumn{7}{|c|}{ First assessment } & \multicolumn{7}{|c|}{ Second assessment } & \multirow{2}{*}{\multicolumn{2}{|c|}{$\begin{array}{l}\text { Agreement } \\
\text { between } \\
\text { physicians }\end{array}$}} \\
\hline & \multirow[t]{2}{*}{$\mathbf{N}$ total } & \multicolumn{2}{|c|}{$\begin{array}{l}\text { Absent } \\
\text { NePC }\end{array}$} & \multicolumn{2}{|c|}{$\begin{array}{l}\text { Present } \\
\text { NePC }\end{array}$} & \multirow[t]{2}{*}{$p$-value } & \multirow[t]{2}{*}{$\boldsymbol{V}$} & \multirow[t]{2}{*}{$\mathbf{N}$ total } & \multicolumn{2}{|c|}{$\begin{array}{l}\text { Absent } \\
\text { NePC }\end{array}$} & \multicolumn{2}{|c|}{$\begin{array}{l}\text { Present } \\
\text { NePC }\end{array}$} & \multirow[t]{2}{*}{$p$-value } & \multirow[t]{2}{*}{$\boldsymbol{v}$} & & \\
\hline & & $\mathbf{n}$ & $\%$ & $\mathbf{n}$ & $\%$ & & & & $\mathbf{n}$ & $\%$ & $\mathbf{n}$ & $\%$ & & & $\mathbf{K}$ & PA (\%) \\
\hline \multicolumn{17}{|c|}{ Touch (finger) } \\
\hline Sensation & 290 & 58 & 95 & 169 & 95 & 0.964 & 0.003 & 289 & 58 & 97 & 168 & 96 & 0.965 & 0.003 & 0.177 & 93.3 \\
\hline Unpleasant & 288 & 57 & 35 & 168 & 45 & 0.181 & 0.089 & 289 & 58 & 33 & 168 & 48 & 0.049 & 0.131 & 0.378 & 69.5 \\
\hline Painful & 286 & 57 & 28 & 167 & 37 & 0.215 & 0.083 & 288 & 57 & 25 & 168 & 41 & 0.026 & 0.149 & 0.315 & 68.8 \\
\hline \multicolumn{17}{|l|}{ Heat } \\
\hline Sensation & 283 & 57 & 91 & 166 & 68 & 0.001 & 0.230 & 287 & 57 & 91 & 167 & 66 & 0.000 & 0.247 & 0.435 & 77.6 \\
\hline Unpleasant & 283 & 57 & 16 & 166 & 16 & 0.707 & 0.056 & 287 & 57 & 16 & 167 & 21 & 0.396 & 0.057 & 0.319 & 79.9 \\
\hline Painful & 283 & 57 & 7 & 166 & 9 & 0.626 & 0.065 & 287 & 57 & 12 & 167 & 14 & 0.775 & 0.019 & 0.258 & 90.0 \\
\hline \multicolumn{17}{|l|}{ Cold } \\
\hline Sensation & 275 & 55 & 93 & 165 & 75 & 0.016 & 0.194 & 284 & 58 & 93 & 168 & 75 & 0.003 & 0.196 & 0.320 & 77.6 \\
\hline Unpleasant & 274 & 55 & 2 & 164 & 12 & 0.052 & 0.164 & 284 & 58 & 7 & 168 & 11 & 0.338 & 0.064 & 0.333 & 87.6 \\
\hline Painful & 273 & 54 & 0 & 164 & 5 & 0.178 & 0.126 & 284 & 58 & 2 & 168 & 6 & 0.197 & 0.086 & 0.477 & 95.4 \\
\hline \multicolumn{17}{|c|}{ Touch (brush I time) } \\
\hline Sensation & 288 & 58 & 93 & 167 & 81 & 0.104 & 0.142 & 286 & 57 & 93 & 167 & 79 & 0.017 & 0.160 & 0.264 & 79.6 \\
\hline Unpleasant & 288 & 58 & 2 & 167 & 7 & 0.156 & 0.095 & 287 & 57 & 2 & 168 & 7 & 0.132 & 0.100 & 0.384 & 93.7 \\
\hline Painful & 288 & 58 & 0 & 167 & 2 & 0.234 & 0.079 & 287 & 57 & 0 & 168 & 4 & 0.148 & 0.096 & 0.387 & 97.3 \\
\hline \multicolumn{17}{|c|}{ Touch (brush 3 times) } \\
\hline Sensation & 290 & 58 & 97 & 169 & 85 & 0.021 & 0.153 & 289 & 58 & 91 & 169 & 80 & 0.055 & 0.127 & 0.303 & 82.7 \\
\hline Unpleasant & 291 & 58 & 2 & 170 & 7 & 0.130 & 0.100 & 290 & 58 & 0 & 169 & 12 & 0.006 & 0.182 & 0.197 & 89.4 \\
\hline Painful & 291 & 58 & 0 & 170 & 2 & 0.308 & 0.067 & 290 & 58 & 0 & 169 & 5 & 0.092 & 0.112 & 0.351 & 96.9 \\
\hline Wind-up & 284 & 56 & 0 & 167 & 8 & 0.056 & 0.161 & 276 & 50 & 0 & 164 & 12 & 0.029 & 0.182 & 0.188 & 87.1 \\
\hline \multicolumn{17}{|c|}{ Pricking (safety pin) } \\
\hline Sensation & 289 & 58 & 95 & 168 & 79 & 0.006 & 0.183 & 290 & 58 & 91 & 169 & 82 & 0.080 & 0.116 & 0.240 & 79.6 \\
\hline Unpleasant & 290 & 58 & 19 & 169 & 31 & 0.180 & 0.123 & 290 & 58 & 24 & 169 & 31 & 0.298 & 0.069 & 0.357 & 73.4 \\
\hline Painful & 290 & 58 & 10 & 169 & 20 & 0.227 & 0.114 & 290 & 58 & 16 & 169 & 21 & 0.388 & 0.057 & 0.286 & 78.3 \\
\hline \multicolumn{17}{|c|}{ Pricking (von Frey hair) } \\
\hline Sensation & 289 & 58 & 91 & 168 & 68 & 0.003 & 0.230 & 288 & 57 & 91 & 169 & 68 & 0.001 & 0.229 & 0.455 & 79.0 \\
\hline Unpleasant & 289 & 58 & 7 & 168 & 14 & 0.228 & 0.114 & 288 & 58 & 16 & 167 & 20 & 0.475 & 0.048 & 0.329 & 81.6 \\
\hline Painful & 289 & 58 & 3 & 168 & 7 & 0.473 & 0.081 & 288 & 58 & 12 & 167 & 10 & 0.590 & 0.036 & 0.402 & 90.6 \\
\hline \multicolumn{17}{|l|}{ Vibration } \\
\hline Sensation & 291 & 58 & 79 & 170 & 69 & 0.060 & 0.157 & 288 & 58 & 81 & 167 & 66 & 0.089 & 0.147 & 0.358 & 73.3 \\
\hline Unpleasant & 290 & 57 & 5 & 170 & 10 & 0.528 & 0.075 & 290 & 58 & 5 & 169 & 11 & 0.275 & 0.107 & 0.225 & 85.4 \\
\hline Painful & 291 & 58 & 3 & 170 & 8 & 0.517 & 0.076 & 290 & 58 & 0 & 169 & 7 & 0.114 & 0.138 & 0.435 & 93.0 \\
\hline
\end{tabular}

Notes: Classification of the presence of NePC is based on physicians' assessment of the patient. $n$, the number of patients; \%, the percentage of positive answers (yes) on the questions: Sensation: Is there a sensation?; Unpleasant: Is the sensation unpleasant?; Painful: Is the sensation painful?; $p$-value= $p$-value for statistical significant difference between groups (outcome of chi-square test, $p \leq 0.05$ ). Bold values are statistically significant $(p \leq 0.05)$.

Abbreviation: NePC, neuropathic pain component; $\mathrm{V}$, value of Cramér's V; K, Kappa value; PA, percentage of agreement.

to instrument availability and the associated costs in all participating sites. BSE as used in our study is easy to learn (one training session before execution of the study) and to carry out in daily clinical practice. Another strength of the study is that we included a range of locations and a large group of patients with chronic pain arising from different origins, which is comparable to patients in a daily clinical (pain) practice. A limitation of the BSE examination is that we only used the question "Is there a sensation?" This may have led to a lower estimation of the outcomes because the patients and/or physicians may have interpreted the question was only being related to the presence of hypoesthesia, hypoalgesia, or analgesia (answer "no": negative signs) rather than assessing the presence of hyperalgesia or allodynia positively (answer "yes"). In a following study, we will change this to a more open question that can be interpreted both ways. We did not use verbal standardized instructions, although all participating professionals were trained in a standardized way and so this is another possible limitation of our BSE method. This may have led to differences in the questioning by the physicians, thereby influencing the patients' answers and the test outcome. The order of the BSE tests was not randomized and so there may be an order effect resulting from the previously performed test. Moreover, both physicians tested the same 
Table 3 Patient NASQ values related to physicians' agreement for the presence of an NePC

\begin{tabular}{|c|c|c|c|c|c|c|c|c|c|c|}
\hline \multirow[b]{3}{*}{ Pressure } & \multirow[b]{3}{*}{ Summed total } & \multicolumn{2}{|c|}{ Total group } & \multicolumn{2}{|c|}{$\begin{array}{l}\text { Congruent } \\
\text { outcome by the } \\
\text { physicians }\end{array}$} & \multicolumn{2}{|c|}{ Absent NePC } & \multicolumn{2}{|c|}{ Present NePC } & \multirow{3}{*}{$\begin{array}{l}p \text {-value } \\
0.718^{b}\end{array}$} \\
\hline & & \multicolumn{2}{|l|}{$\overline{\mathbf{N}}$} & \multicolumn{2}{|l|}{$\overline{\mathbf{N}}$} & \multicolumn{2}{|l|}{$\mathbf{N}$} & \multicolumn{2}{|l|}{$\mathbf{N}$} & \\
\hline & & 39 & $872(5 \mid 6 ; 1117)$ & 30 & $858(506 ; 1 / 25)$ & 5 & $846(729 ; 1086)$ & 25 & $929(465 ; 1 \mid 32)$ & \\
\hline \multirow[t]{2}{*}{$(\mathrm{kPa})$} & Central & 56 & $866(542 ; 1068)$ & 43 & $872(545 ; 1058)$ & 15 & $892(600 ; 989)$ & 28 & $793(435 ; 1068)$ & $0.558^{\mathrm{b}}$ \\
\hline & Peripheral & 39 & $794(526 ; 1084)$ & 30 & $793(5 \mid 6 ; 1095)$ & 5 & $800(701 ; 1066)$ & 25 & $787(488 ; 1106)$ & $0.676^{\mathrm{b}}$ \\
\hline \multirow[t]{5}{*}{ CPM } & Positive & 23 & $58 \%$ & 19 & $61 \%$ & 3 & $60 \%$ & 16 & $62 \%$ & $0.948^{\mathrm{a}}$ \\
\hline & Negative & 17 & $43 \%$ & 12 & $39 \%$ & 2 & $40 \%$ & 10 & $39 \%$ & \\
\hline & No change & & & & & & & & & \\
\hline & Response & 40 & $|3|(-13 ; 225)$ & 31 & $109(3 ; 221)$ & 5 & $13(-3|;| 76)$ & 26 & I 55 (24;222) & $0.259^{b}$ \\
\hline & CPM value & 40 & $7.2(-14 ; 25)$ & 31 & $7(-18 ; 23)$ & 5 & $3(-19 ; 16)$ & 26 & $8.0(-16 ; 34)$ & $0.591^{b}$ \\
\hline EPDT $(m A)$ & Total mean & 53 & $11(7 ; 17)$ & 42 & $12(8 ; 17)$ & 16 & II $(6 ; 20)$ & 26 & $12(8 ; 17)$ & $0.969^{b}$ \\
\hline \multirow[t]{5}{*}{ CPM } & Positive & 13 & $81 \%$ & 10 & $40 \%$ & 8 & $80 \%$ & 2 & $100 \%$ & $0.488^{\mathrm{a}}$ \\
\hline & Negative & 3 & $19 \%$ & 2 & $8 \%$ & 2 & $20 \%$ & 0 & $--^{c}$ & \\
\hline & No change & & & 13 & $52 \%$ & & & & & \\
\hline & Response & 16 & $0.8(0.03 ; 4)$ & 12 & $2(0.2 ; 5)$ & 10 & $2(-0.05 ; 4.0)$ & 2 & $3(0.4 ;---)^{c}$ & $0.747^{b}$ \\
\hline & CPM value & 16 & $7.7(0.3 ; 30)$ & 12 & $20(3 ; 34)$ & 10 & $15(-0.2 ; 37)$ & 2 & $26(18 ;---)^{c}$ & $0.667^{b}$ \\
\hline EPTT (mA) & Total mean & 25 & $10(8 ; 22)$ & 19 & I3 (8;23) & 3 & $13(10 ;---)^{c}$ & 16 & $12(8 ; 22)$ & $0.314^{b}$ \\
\hline \multirow[t]{5}{*}{ CPM } & Positive & 17 & $68 \%$ & 13 & $68 \%$ & 3 & $100 \%$ & 10 & $63 \%$ & $0.200^{\mathrm{a}}$ \\
\hline & Negative & 8 & $32 \%$ & 6 & $32 \%$ & 0 & $--^{c}$ & 6 & $38 \%$ & \\
\hline & No change & & & & & & & & & \\
\hline & Response & 25 & $0.5(-0.2 ; 2)$ & 19 & $0.5(-0.2 ; 2)$ & 3 & $2(1 ;---)^{c}$ & 16 & $0.4(-0.3 ; 2)$ & $0.117^{b}$ \\
\hline & CPM value & 25 & $7(-2 ; 16)$ & 19 & $7(-2 ; 17)$ & 3 & $12(9 ;---)^{c}$ & 16 & $4.8(-3 ; 16)$ & $0.219^{b}$ \\
\hline IWB test & Latency (s) & 41 & $20(10 ; 170)$ & 32 & $40(10 ; 180)$ & 5 & $40(10 ; 170)$ & 27 & $40(10 ; 180)$ & $0.960^{\mathrm{b}}$ \\
\hline
\end{tabular}

Notes: Classification of presence of NePC is based on physicians' assessment of the patients. Absent, NePC is absent; Present, NePC is present; Undetermined, both physicians disagree with each other about the existence of an NePC; $\mathrm{N}$, number of patients in the analysis; CPM > $\pm 10 \%$ : patients included in the analysis with a CPM of more than $10 \%$ difference from zero. ${ }^{a}$ Chi-square test; ${ }^{b}$ Mann-Whitney $U$-test. $p \leq 0.05$ is considered statistically significant; ${ }^{\circ}$ due to the low number of patients in the analysis, IQR is not given in the $75 \%$ range.

Abbreviations: NASQ, Nijmegen-Aalborg screening quantitative sensory testing; NePC, neuropathic pain component; CPM, Conditioned pain modulation; EPDT, electrical pain detection threshold; EPTT, electrical pain tolerance threshold; IWB, ice water bucket; IQR, interquartile range.

patient directly following each other. Although the second physician was not aware of the first results, this may have also influenced our results. Furthermore, there was no correction for multiple testing while several statistical analyses were performed. Because of this, the results must be interpreted with caution.

Another possible limitation is the fact that we only included a small group of patients with chronic pain measured via NASQ; 8 patients with sPND. This may have affected our outcome because they have a different disease origin compared to patients with LBLP or NSAP. For future NASQ research, we would suggest collecting normative data preferably matched for age, sex, and education level. With these data, the value of NASQ for clinical monitoring disease progression and the response of individual patients on treatment can be evaluated.

\section{Conclusion}

Using a standardized BSE to assess sensory dysfunction indicating the presence or absence of an $\mathrm{NePC}$ appears to be preferable compared to the NASQ paradigm in patients with chronic pain. However, further development of both assessments is desirable. The BSE should be adapted to detect sensory differences between absent and present NePC; the NASQ paradigm should be able to measure altered pain processing and endogenous pain modulation in patients with chronic pain due to present or absent NePC. We postulate that this will lead to a greater contribution to the assessment of neuropathic components of patients' pain.

\section{Acknowledgment}

We would like to thank all the participating patients, physicians and assistants for their invaluable work in this study.

\section{Disclosure}

This study was performed within DALI for PAIN, a national program that focuses on neuropathic pain care optimalisation. DALI for PAIN is an initiative of Pfizer. This project was supported by an unrestricted grant from Pfizer. The funders had no role in study design, data collection and analysis, decision to publish, or preparation of the manuscript. The authors report no other conflicts of interest in this work. 


\section{References}

1. IASP. IASP taxonomy neuropathic pain. 2015. Available from: http:// www.iasp-pain.org/Taxonomy\#Neuropathicpain. Accessed May 19, 2015.

2. Dieleman JP, Kerklaan J, Huygen FJ, Bouma PA, Sturkenboom MC. Incidence rates and treatment of neuropathic pain conditions in the general population. Pain. 2008;137(3):681-688.

3. Freynhagen R, Bennett MI. Diagnosis and management of neuropathic pain. BMJ. 2009;339:b3002.

4. Bouhassira D, Lantéri-Minet M, Attal N, Laurent B, Touboul C. Prevalence of chronic pain with neuropathic characteristics in the general population. Pain. 2008;136(3):380-387.

5. La Cesa S, Tamburin S, Tugnoli V, et al. How to diagnose neuropathic pain? The contribution from clinical examination, pain questionnaires and diagnostic tests. Neurol Sci. 2015;36(12):2169-2175.

6. Haanpää M, Attal N, Backonja M, et al. NeuPSIG guidelines on neuropathic pain assessment. Pain. 2011;152(1):14-27.

7. Haanpää ML, Backonja MM, Bennett MI, et al. Assessment of neuropathic pain in primary care. Am J Med. 2009;122(10 Suppl):S13-S21.

8. Truini A, Cruccu G. How diagnostic tests help to disentangle the mechanisms underlying neuropathic pain symptoms in painful neuropathies. Pain. 2016;157(Suppl 1):S53-S59.

9. Treede RD, Jensen TS, Campbell JN, et al. Neuropathic pain: redefinition and a grading system for clinical and research purposes. Neurology. 2008;70(18):1630-1635.

10. Finnerup NB, Haroutounian S, Kamerman P, et al. Neuropathic pain: an updated grading system for research and clinical practice. Pain. 2016;157(8):1599-1606.

11. Rolke R, Baron R, Maier C, et al. Quantitative sensory testing in the German Research Network on Neuropathic Pain (DFNS): standardized protocol and reference values. Pain. 2006;123(3):231-243.

12. Rolke R, Magerl W, Campbell KA, et al. Quantitative sensory testing: a comprehensive protocol for clinical trials. Eur J Pain. 2006;10(1):77-88

13. Backonja MM, Walk D, Edwards RR, et al. Quantitative sensory testing in measurement of neuropathic pain phenomena and other sensory abnormalities. Clin J Pain. 2009;25(7):641-647.

14. Arendt-Nielsen L, Yarnitsky D. Experimental and clinical applications of quantitative sensory testing applied to skin, muscles and viscera. J Pain. 2009;10(6):556-572.

15. Wilder-Smith OH. A Paradigm-Shift in Pain Medicine: Implementing a Systematic Approach to Altered Pain Processing in Everyday Clinical Practice Based on Quantitative Sensory Testing. Aalborg: Center for Sensory-Motor Interaction (SMI), Department of Health Science and Technology, Aalborg University; 2013.

16. Bouwense SA, de Vries M, Schreuder LT, et al. Systematic mechanismorientated approach to chronic pancreatitis pain. World J Gastroenterol. 2015;21(1):47-59.

17. Yarnitsky D. Conditioned pain modulation (the diffuse noxious inhibitory control-like effect): its relevance for acute and chronic pain states. Curr Opin Anaesthesiol. 2010;23(5):611-615.

18. Yarnitsky D. Role of endogenous pain modulation in chronic pain mechanisms and treatment. Pain. 2015;156(Suppl 1):S24-S31.

19. Hansson P, Backonja M, Bouhassira D. Usefulness and limitations of quantitative sensory testing: clinical and research application in neuropathic pain states. Pain. 2007;129(3):256-259.

20. Geber C, Klein T, Azad S, et al. Test-retest and interobserver reliability of quantitative sensory testing according to the protocol of the German Research Network on Neuropathic Pain (DFNS): a multi-centre study. Pain. 2011;152(3):548-556.
21. Cruccu G, Sommer C, Anand P, et al. EFNS guidelines on neuropathic pain assessment: revised 2009. Eur J Neurol. 2010;17(8):1010-1018.

22. Krumova EK, Geber C, Westermann A, Maier C. Neuropathic pain: is quantitative sensory testing helpful? Curr Diab Rep. 2012;12(4): 393-402.

23. Woolf CJ. Central sensitization: implications for the diagnosis and treatment of pain. Pain. 2011;152(3 Suppl):S2-S15.

24. Chua NHL, Timmerman H, Vissers KC, OH W-S. Multi-modal quantitative sensory testing in patients with unilateral chronic neck pain: an exploratory study. J Musculoskelet Pain. 2012;20(4):292-299.

25. Pud D, Granovsky Y, Yarnitsky D. The methodology of experimentally induced diffuse noxious inhibitory control (DNIC)-like effect in humans. Pain. 2009;144(1-2):16-19.

26. Corrêa JB, Costa LO, de Oliveira NT, Sluka KA, Liebano RE. Central sensitization and changes in conditioned pain modulation in people with chronic nonspecific low back pain: a case-control study. Exp Brain Res. 2015;233(8):2391-2399.

27. Yarnitsky D, Arendt-Nielsen L, Bouhassira D, et al. Recommendations on terminology and practice of psychophysical DNIC testing. Eur $J$ Pain. 2010;14(4):339.

28. Timmerman H, Wilder-Smith O, van Weel C, Wolff A, Vissers K. Detecting the neuropathic pain component in the clinical setting: a study protocol for validation of screening instruments for the presence of a neuropathic pain component. BMC Neurol. 2014;14(1):94.

29. Timmerman H, Wolff AP, Schreyer T, et al. Cross-cultural adaptation to the Dutch language of the PainDETECT-Questionnaire. Pain Pract. 2013;13(3):206-214.

30. Van Seventer R, Vos C, Meerding W, et al. Linguistic validation of the DN4 for use in international studies. Eur J Pain. 2010;14(1):58-63.

31. Timmerman $\mathrm{H}$, Steegers MAH, Huygen F, et al. Investigating the validity of the DN4 in a consecutive population of patients with chronic pain. PLoS One. 2017;12(11):e0187961.

32. Freynhagen R, Baron R, Gockel U, Tölle TR. PainDETECT: a new screening questionnaire to identify neuropathic components in patients with back pain. Curr Med Res Opin. 2006;22(10):1911-1920.

33. Bouhassira D, Attal N, Alchaar H, et al. Comparison of pain syndromes associated with nervous or somatic lesions and development of a new neuropathic pain diagnostic questionnaire (DN4). Pain. 2005;114(1-2):29-36.

34. Cruccu G, Anand P, Attal N, et al. EFNS guidelines on neuropathic pain assessment. Eur J Neurol. 2004;11(3):153-162.

35. Baron R, Binder A, Wasner G. Neuropathic pain: diagnosis, pathophysiological mechanisms, and treatment. Lancet Neurol. 2010;9(8):807-819.

36. Cruccu G, Truini A. Tools for assessing neuropathic pain. PLoS Med. 2009;6(4):e1000045.

37. Backonja MM, Attal N, Baron R, et al. Value of quantitative sensory testing in neurological and pain disorders: NeuPSIG consensus. Pain. 2013;154(9):1807-1819.

38. Granovsky Y. Conditioned pain modulation: a predictor for development and treatment of neuropathic pain. Curr Pain Headache Rep. 2013;17(9):361

39. Graven-Nielsen T, Arendt-Nielsen L. Assessment of mechanisms in localized and widespread musculoskeletal pain. Nat Rev Rheumatol. 2010;6(10):599-606.

40. Pfau DB, Geber C, Birklein F, Treede RD. Quantitative sensory testing of neuropathic pain patients: potential mechanistic and therapeutic implications. Curr Pain Headache Rep. 2012;16(3): 199-206. 


\section{Supplementary material}

Table SI Bedside examination outcome based on inter physician agreement on the presence of an NePC for the total group and for patients with LBLP, NSAP, or sPND separately

\begin{tabular}{|c|c|c|c|c|c|c|c|c|c|c|c|c|c|c|c|c|c|}
\hline & & \multicolumn{7}{|c|}{ First assessment } & \multicolumn{7}{|c|}{ Second assessment } & \multirow{2}{*}{\multicolumn{2}{|c|}{$\begin{array}{l}\text { Agreement } \\
\text { between } \\
\text { physicians }\end{array}$}} \\
\hline & & \multirow[t]{2}{*}{$\mathbf{N}$ total } & \multicolumn{2}{|c|}{$\begin{array}{l}\text { Absent } \\
\text { NePC }\end{array}$} & \multicolumn{2}{|c|}{$\begin{array}{l}\text { Present } \\
\text { NePC }\end{array}$} & \multirow[t]{2}{*}{ p-value } & \multirow[t]{2}{*}{$v$} & \multirow[t]{2}{*}{$\mathbf{N}$ total } & \multicolumn{2}{|c|}{$\begin{array}{l}\text { Absent } \\
\text { NePC }\end{array}$} & \multicolumn{2}{|c|}{$\begin{array}{l}\text { Present } \\
\text { NePC }\end{array}$} & \multirow[t]{2}{*}{ p-value } & \multirow[t]{2}{*}{$v$} & & \\
\hline & & & $\mathbf{n}$ & $\%$ & n & $\%$ & & & & $n$ & $\%$ & $n$ & $\%$ & & & $K$ & $P A(\%)$ \\
\hline \multicolumn{18}{|l|}{ Touch (finger) } \\
\hline \multirow[t]{4}{*}{ Sensation } & Total & 290 & 58 & 95 & 169 & 95 & 0.964 & 0.003 & 289 & 58 & 97 & 168 & 96 & 0.965 & 0.003 & 0.177 & 93.3 \\
\hline & LBLP & $|3|$ & 28 & 100 & 74 & 99 & 0.536 & 0.061 & 132 & 28 & 100 & 75 & 96 & 0.283 & 0.106 & -0.015 & 96.0 \\
\hline & NSAP & 51 & 18 & 89 & 23 & 91 & 0.796 & 0.040 & 50 & 18 & 94 & 22 & 95 & 0.884 & 0.023 & 0.787 & 97.5 \\
\hline & sPND & 108 & 12 & 92 & 72 & 92 & 1.000 & 0.000 & 107 & 12 & 92 & 71 & 97 & 0.344 & 0.104 & -0.053 & 91.3 \\
\hline Unpleasant & Total & 288 & 57 & 35 & 168 & 45 & 0.181 & 0.089 & 289 & 58 & 33 & 168 & 48 & 0.049 & 0.131 & 0.378 & 69.5 \\
\hline & LBLP & 130 & 27 & 22 & 74 & 30 & 0.456 & 0.074 & 132 & 28 & 25 & 75 & 28 & 0.761 & 0.030 & 0.242 & 70.3 \\
\hline & NSAP & 51 & 18 & 44 & 23 & 44 & 0.951 & 0.010 & 50 & 18 & 33 & 22 & 45 & 0.436 & 0.123 & 0.388 & 70.0 \\
\hline & sPND & 107 & 12 & 50 & 71 & 62 & 0.433 & 0.086 & 107 & 12 & 50 & 71 & 69 & 0.198 & 0.141 & 0.318 & 68.3 \\
\hline Painful & Total & 286 & 57 & 28 & 167 & 37 & 0.215 & 0.083 & 288 & 57 & 25 & 168 & 41 & 0.026 & 0.149 & 0.315 & 68.8 \\
\hline & LBLP & 130 & 27 & 19 & 74 & 22 & 0.734 & 0.034 & 132 & 28 & 18 & 75 & 43 & 0.425 & 0.079 & 0.202 & 73.3 \\
\hline & NSAP & 51 & 18 & 33 & 23 & 44 & 0.509 & 0.103 & 50 & 18 & 28 & 22 & 41 & 0.386 & 0.137 & 0.297 & 67.5 \\
\hline & sPND & 105 & 12 & 42 & 70 & 51 & 0.532 & 0.069 & 106 & II & 36 & 71 & 58 & 0.185 & 0.146 & 0.275 & 63.8 \\
\hline Heat & & & & & & & & & & & & & & & & & \\
\hline Sensation & Total & 283 & 57 & 91 & 166 & 68 & 0.001 & 0.230 & 287 & 57 & 91 & 167 & 66 & 0.000 & 0.247 & 0.435 & 77.6 \\
\hline & LBLP & 127 & 27 & 96 & 71 & 69 & 0.004 & 0.288 & $13 \mid$ & 27 & 96 & 75 & 68 & 0.003 & 0.290 & 0.579 & 84.5 \\
\hline & NSAP & 48 & 18 & 89 & 23 & 74 & 0.230 & 0.188 & 50 & 18 & 100 & 22 & 86 & 0.103 & 0.258 & 0.286 & 82.5 \\
\hline & sPND & 108 & 12 & 83 & 72 & 65 & 0.215 & 0.135 & 106 & 12 & 67 & 70 & 57 & 0.536 & 0.068 & 0.301 & 67.1 \\
\hline Unpleasant & Total & 283 & 57 & 16 & 166 & 16 & 0.707 & 0.056 & 287 & 57 & 16 & 167 & 21 & 0.396 & 0.057 & 0.319 & 79.9 \\
\hline & LBLP & 127 & 27 & 22 & 71 & 8 & 0.153 & 0.196 & 131 & 27 & 19 & 75 & 13 & 0.514 & 0.065 & 0.117 & 79.4 \\
\hline & NSAP & 48 & 18 & 6 & 23 & 9 & 0.702 & 0.060 & 50 & 18 & 6 & 22 & 18 & 0.230 & 0.190 & 0.231 & 87.5 \\
\hline & sPND & 108 & 12 & 17 & 72 & 25 & 0.742 & 0.084 & 106 & 12 & 25 & 70 & 30 & 0.725 & 0.039 & 0.424 & 76.8 \\
\hline Painful & Total & 283 & 57 & 7 & 166 & 9 & 0.626 & 0.065 & 287 & 57 & 12 & 167 & 14 & 0.775 & 0.019 & 0.258 & 90.0 \\
\hline & LBLP & 127 & 27 & 7 & 71 & 3 & 0.494 & 0.120 & $|3|$ & 27 & 11 & 75 & 8 & 0.625 & 0.048 & -0.057 & 87.6 \\
\hline & NSAP & 48 & 18 & 6 & 23 & 9 & 0.702 & 0.060 & 50 & 18 & 6 & 22 & 14 & 0.397 & 0.134 & 0.286 & 90.0 \\
\hline & sPND & 108 & 12 & 8 & 72 & 15 & $0.74 I$ & 0.084 & 106 & 12 & 25 & 70 & 20 & 0.693 & 0.044 & 0.355 & 80.5 \\
\hline Cold & & & & & & & & & & & & & & & & & \\
\hline Sensation & Total & 275 & 55 & 93 & 165 & 75 & 0.016 & 0.194 & 284 & 58 & 93 & 168 & 75 & 0.003 & 0.196 & 0.320 & 77.6 \\
\hline & LBLP & 130 & 28 & 96 & 74 & 80 & 0.038 & 0.205 & $|3|$ & 28 & 96 & 75 & 79 & 0.031 & 0.213 & 0.458 & 85.3 \\
\hline & NSAP & 43 & 15 & 87 & 22 & 86 & 0.979 & 0.004 & 50 & 18 & 100 & 22 & 95 & 0.360 & 0.145 & 0.302 & 89.2 \\
\hline & sPND & 102 & 12 & 92 & 69 & 65 & 0.186 & 0.204 & 103 & 12 & 75 & 71 & 65 & 0.489 & 0.076 & 0.148 & 62.5 \\
\hline Unpleasant & Total & 274 & 55 & 2 & 164 & 12 & 0.052 & 0.164 & 284 & 58 & 7 & 168 & 11 & 0.338 & 0.064 & 0.333 & 87.6 \\
\hline & LBLP & 129 & 28 & 4 & 73 & 10 & 0.489 & 0.119 & $|3|$ & 28 & 7 & 75 & 5 & 0.727 & 0.034 & 0.357 & 91.1 \\
\hline & NSAP & 43 & 15 & 0 & 22 & 9 & 0.230 & 0.197 & 50 & 18 & 0 & 22 & 18 & 0.057 & 0.302 & $0.64 I$ & 94.6 \\
\hline & sPND & 102 & 12 & 0 & 69 & 16 & 0.294 & 0.174 & 103 & 12 & 17 & 71 & 15 & 0.918 & 0.011 & 0.217 & 80.0 \\
\hline Painful & Total & 273 & 54 & 0 & 164 & 5 & 0.178 & 0.126 & 284 & 58 & 2 & 168 & 6 & 0.197 & 0.086 & 0.477 & 95.4 \\
\hline & LBLP & 129 & 28 & 0 & 73 & 0 & 0.534 & 0.062 & $|3|$ & 28 & 4 & 75 & I & 0.464 & 0.072 & -0.007 & 97.0 \\
\hline & NSAP & 42 & 14 & 0 & 22 & 5 & 0.418 & 0.135 & 50 & 18 & 0 & 22 & 14 & 0.103 & 0.258 & 0.478 & 94.4 \\
\hline & sPND & 102 & 12 & 0 & 69 & 10 & 0.462 & 0.138 & 103 & 12 & 0 & 71 & 8 & 0.296 & 0.115 & 0.582 & 93.8 \\
\hline Touch (brush & me) & & & & & & & & & & & & & & & & \\
\hline Sensation & Total & 288 & 58 & 93 & 167 & 81 & 0.104 & 0.142 & 286 & 57 & 93 & 167 & 79 & 0.017 & 0.160 & 0.264 & 79.6 \\
\hline & LBLP & 130 & 28 & 100 & 73 & 90 & 0.089 & 0.169 & 132 & 28 & 100 & 75 & 88 & 0.055 & 0.189 & 0.187 & 88.1 \\
\hline & NSAP & 51 & 18 & 89 & 23 & 96 & 0.409 & 0.129 & 48 & 17 & 100 & 22 & 86 & 0.113 & 0.254 & 0.278 & 89.7 \\
\hline & sPND & 107 & 12 & 83 & 71 & 68 & 0.533 & 0.123 & 106 & 12 & 67 & 70 & 67 & 0.974 & 0.004 & 0.178 & 64.2 \\
\hline Unpleasant & Total & 288 & 58 & 2 & 167 & 7 & 0.156 & 0.095 & 287 & 57 & 2 & 168 & 7 & 0.132 & 0.100 & 0.384 & 93.7 \\
\hline & LBLP & 130 & 28 & 4 & 73 & 6 & 0.826 & 0.022 & 132 & 28 & 0 & 75 & 3 & 0.383 & 0.086 & 0.385 & 97.0 \\
\hline & NSAP & 51 & 18 & 0 & 23 & 9 & 0.200 & 0.200 & 48 & 17 & 0 & 22 & 18 & 0.063 & 0.297 & 0.374 & 62.3 \\
\hline & sPND & 107 & 12 & 0 & 71 & 10 & 0.256 & 0.125 & 106 & 12 & 8 & 71 & 8 & 0.989 & 0.001 & 0.375 & 90.2 \\
\hline
\end{tabular}


Table SI (Continued)

\begin{tabular}{|c|c|c|c|c|c|c|c|c|c|c|c|c|c|c|c|c|c|}
\hline & & \multicolumn{7}{|c|}{ First assessment } & \multicolumn{7}{|c|}{ Second assessment } & \multirow{2}{*}{\multicolumn{2}{|c|}{$\begin{array}{l}\text { Agreement } \\
\text { between } \\
\text { physicians }\end{array}$}} \\
\hline & & \multirow[t]{2}{*}{$\mathbf{N}$ total } & \multicolumn{2}{|c|}{$\begin{array}{l}\text { Absent } \\
\text { NePC }\end{array}$} & \multicolumn{2}{|c|}{$\begin{array}{l}\text { Present } \\
\text { NePC }\end{array}$} & \multirow[t]{2}{*}{$p$-value } & \multirow[t]{2}{*}{$\boldsymbol{V}$} & \multirow[t]{2}{*}{$\mathbf{N}$ total } & \multicolumn{2}{|c|}{$\begin{array}{l}\text { Absent } \\
\text { NePC }\end{array}$} & \multicolumn{2}{|c|}{$\begin{array}{l}\text { Present } \\
\text { NePC }\end{array}$} & \multirow[t]{2}{*}{$p$-value } & \multirow[t]{2}{*}{$\boldsymbol{v}$} & & \\
\hline & & & $\mathbf{n}$ & $\%$ & $\mathbf{n}$ & $\%$ & & & & $\mathbf{n}$ & $\%$ & $\mathbf{n}$ & $\%$ & & & $K$ & PA (\%) \\
\hline Painful & Total & 288 & 58 & 0 & 167 & 2 & 0.234 & 0.079 & 287 & 57 & 0 & 168 & 4 & 0.148 & 0.096 & 0.387 & 97.3 \\
\hline & LBLP & 130 & 28 & 0 & 73 & 1 & 0.534 & 0.062 & 132 & 28 & 0 & 75 & 3 & 0.383 & 0.086 & -0.013 & 97.0 \\
\hline & NSAP & 51 & 18 & 0 & 23 & 0 & --- & --- & 48 & 17 & 0 & 22 & 5 & 0.373 & 0.143 & 0.000 & 97.4 \\
\hline & sPND & 107 & 12 & 0 & 71 & 4 & 0.468 & 0.080 & 107 & 12 & 0 & 71 & 4 & 0.468 & 0.080 & 0.654 & 97.6 \\
\hline Touch (brush & mes) & & & & & & & & & & & & & & & & \\
\hline Sensation & Total & 290 & 58 & 97 & 169 & 85 & 0.021 & 0.153 & 289 & 58 & 91 & 169 & 80 & 0.055 & 0.127 & 0.303 & 82.7 \\
\hline & LBLP & 132 & 28 & 100 & 75 & 96 & 0.283 & 0.106 & 132 & 28 & 100 & 75 & 93 & 0.161 & 0.138 & 0.222 & 94.2 \\
\hline & NSAP & 51 & 18 & 89 & 23 & 96 & 0.409 & 0.129 & 50 & 18 & 100 & 22 & 86 & 0.103 & 0.258 & 0.279 & 90.0 \\
\hline & sPND & 107 & 12 & 100 & 71 & 70 & 0.029 & 0.239 & 107 & 12 & 58 & 72 & 65 & 0.642 & 0.051 & 0.190 & 65.1 \\
\hline Unpleasant & Total & 291 & 58 & 2 & 170 & 7 & 0.130 & 0.100 & 290 & 58 & 0 & 169 & 12 & 0.006 & 0.182 & 0.197 & 89.4 \\
\hline & LBLP & 132 & 28 & 4 & 75 & 5 & 0.711 & 0.036 & 132 & 28 & 0 & 75 & 8 & 0.123 & 0.152 & 0.136 & 91.3 \\
\hline & NSAP & 51 & 18 & 0 & 23 & 87 & 0.200 & 0.200 & 50 & 18 & 0 & 22 & 23 & 0.031 & 0.342 & 0.304 & 90.0 \\
\hline & sPND & 108 & 12 & 0 & 72 & 8 & 0.299 & 0.113 & 108 & 12 & 0 & 72 & 13 & 0.195 & 0.141 & 0.198 & 86.9 \\
\hline Painful & Total & 291 & 58 & 0 & 170 & 2 & 0.308 & 0.067 & 290 & 58 & 0 & 169 & 5 & 0.092 & 0.112 & 0.351 & 96.9 \\
\hline & LBLP & 132 & 28 & 0 & 75 & 3 & 0.383 & 0.086 & 132 & 20 & 0 & 75 & 4 & 0.283 & 0.106 & 0.386 & 97.1 \\
\hline & NSAP & 51 & 18 & 0 & 23 & 0 & --- & --- & 50 & 18 & 0 & 22 & 5 & 0.360 & 0.145 & 0.000 & 97.5 \\
\hline & sPND & 108 & 12 & 0 & 72 & 1 & 0.681 & 0.045 & 108 & 12 & 0 & 72 & 6 & 0.403 & 0.091 & 0.388 & 96.4 \\
\hline Wind-up & Total & 284 & 56 & 0 & 167 & 8 & 0.056 & 0.161 & 276 & 50 & 0 & 164 & 12 & 0.029 & 0.182 & 0.188 & 87.1 \\
\hline & LBLP & $|3|$ & 28 & 0 & 75 & 7 & 0.304 & 0.152 & 125 & 26 & 0 & 71 & 7 & 0.310 & 0.155 & 0.296 & 91.8 \\
\hline & NSAP & 48 & 16 & 0 & 22 & 9 & 0.215 & 0.201 & 44 & 12 & 0 & 22 & 5 & 0.290 & 0.270 & 0.145 & 87.1 \\
\hline & sPND & 105 & 12 & 0 & 70 & 10 & 0.468 & 0.136 & 107 & 12 & 0 & 71 & 15 & 0.143 & 0.161 & 0.116 & 81.5 \\
\hline Pricking (safety & & & & & & & & & & & & & & & & & \\
\hline Sensation & Total & 289 & 58 & 95 & 168 & 79 & 0.006 & 0.183 & 290 & 58 & 91 & 169 & 82 & 0.080 & 0.116 & 0.240 & 79.6 \\
\hline & LBLP & 132 & 28 & 100 & 75 & 85 & 0.032 & 0.211 & 132 & 28 & 100 & 75 & 92 & 0.123 & 0.152 & 0.046 & 85.4 \\
\hline & NSAP & 51 & 18 & 94 & 23 & 91 & 0.702 & 0.060 & 50 & 18 & 100 & 22 & 95 & 0.360 & 0.145 & $0.48 I$ & 95.0 \\
\hline & sPND & 106 & 12 & 25 & 71 & 35 & 0.489 & 0.079 & 108 & 12 & 58 & 72 & 67 & 0.574 & 0.061 & 0.176 & 64.6 \\
\hline Unpleasant & Total & 290 & 58 & 19 & 169 & 31 & 0.180 & 0.123 & 290 & 58 & 24 & 169 & 31 & 0.298 & 0.069 & 0.357 & 73.4 \\
\hline & LBLP & 132 & 28 & 21 & 75 & 31 & 0.519 & 0.113 & 132 & 28 & 32 & 75 & 32 & 0.989 & 0.001 & 0.456 & 76.7 \\
\hline & NSAP & 51 & 18 & 11 & 23 & 17 & 0.572 & 0.088 & 50 & 18 & 11 & 22 & 32 & 0.119 & 0.247 & 0.106 & 72.5 \\
\hline & sPND & 107 & 12 & 25 & 71 & 35 & 0.489 & 0.076 & 108 & 12 & 25 & 72 & 31 & 0.697 & 0.043 & 0.308 & 69.9 \\
\hline Painful & Total & 290 & 58 & 10 & 169 & 20 & 0.227 & 0.114 & 290 & 58 & 16 & 169 & 21 & 0.388 & 0.057 & 0.286 & 78.3 \\
\hline & LBLP & 132 & 28 & 14 & 75 & 15 & 0.826 & 0.061 & 132 & 28 & 18 & 75 & 17 & 0.950 & 0.006 & 0.265 & 79.6 \\
\hline & NSAP & 51 & 18 & 0 & 23 & 13 & 0.111 & 0.249 & 50 & 18 & 11 & 22 & 27 & 0.204 & 0.201 & 0.082 & 77.5 \\
\hline & sPND & 107 & 12 & 17 & 71 & 27 & 0.457 & 0.082 & 108 & 12 & 17 & 72 & 22 & 0.664 & 0.047 & 0.364 & 77.1 \\
\hline Pricking (von F & hair) & & & & & & & & & & & & & & & & \\
\hline Sensation & Total & 289 & 58 & 91 & 168 & 68 & 0.003 & 0.230 & 288 & 57 & 91 & 169 & 68 & 0.001 & 0.229 & 0.455 & 79.0 \\
\hline & LBLP & 132 & 28 & 96 & 75 & 82 & 0.045 & 0.245 & 132 & 28 & 96 & 75 & 75 & 0.013 & 0.245 & 0.291 & 77.7 \\
\hline & NSAP & 51 & 18 & 94 & 23 & 91 & 0.702 & 0.060 & 50 & 18 & 100 & 22 & 91 & 0.189 & 0.208 & 0.787 & 97.5 \\
\hline & sPND & 106 & 12 & 75 & 70 & 54 & 0.180 & 0.148 & 106 & 11 & 64 & 72 & 54 & 0.556 & 0.065 & 0.423 & 71.6 \\
\hline Unpleasant & Total & 289 & 58 & 7 & 168 & 14 & 0.228 & 0.114 & 288 & 58 & 16 & 167 & 20 & 0.475 & 0.048 & 0.329 & 81.6 \\
\hline & LBLP & 132 & 28 & 4 & 75 & 16 & 0.353 & 0.142 & $|3|$ & 28 & 18 & 74 & 14 & 0.580 & 0.055 & 0.171 & 81.4 \\
\hline & NSAP & 51 & 18 & 0 & 23 & 13 & 0.111 & 0.249 & 50 & 18 & 11 & 22 & 32 & 0.119 & 0.247 & 0.437 & 85.0 \\
\hline & sPND & 106 & 12 & 25 & 70 & 17 & 0.752 & 0.083 & 107 & 12 & 17 & 71 & 23 & 0.648 & 0.050 & 0.410 & 80.2 \\
\hline Painful & Total & 289 & 58 & 3 & 168 & 7 & 0.473 & $0.08 I$ & 288 & 58 & 12 & 167 & 10 & 0.590 & 0.036 & 0.402 & 90.6 \\
\hline & LBLP & 132 & 28 & 4 & 75 & 4 & 0.823 & 0.062 & 131 & 28 & 14 & 74 & 8 & 0.349 & 0.093 & 0.292 & 90.2 \\
\hline & NSAP & 51 & 18 & 0 & 23 & 8 & 0.111 & 0.249 & 50 & 18 & 6 & 22 & 14 & 0.397 & 0.134 & 0.531 & 92.5 \\
\hline & sPND & 106 & 12 & 8 & 70 & 7 & 0.909 & 0.048 & 107 & 12 & 17 & 71 & 10 & 0.483 & 0.077 & 0.450 & 90.1 \\
\hline Vibration & & & & & & & & & & & & & & & & & \\
\hline Sensation & Total & 291 & 58 & 79 & 170 & 69 & 0.060 & 0.157 & 288 & 58 & 81 & 167 & 66 & 0.089 & 0.147 & 0.358 & 73.3 \\
\hline & LBLP & 132 & 28 & 71 & 75 & 68 & 0.218 & 0.172 & $13 \mid$ & 28 & 71 & 74 & 58 & 0.217 & 0.122 & 0.446 & 74.5 \\
\hline & NSAP & 51 & 18 & 89 & 23 & 78 & 0.369 & 0.140 & 50 & 18 & 94 & 22 & 91 & 0.673 & 0.067 & 0.136 & 82.5 \\
\hline & sPND & 108 & 12 & 83 & 72 & 68 & 0.284 & 0.117 & 107 & 12 & 83 & 71 & 66 & 0.484 & 0.132 & 0.242 & 67.5 \\
\hline
\end{tabular}


Table SI (Continued)

\begin{tabular}{|c|c|c|c|c|c|c|c|c|c|c|c|c|c|c|c|c|c|}
\hline & & \multicolumn{7}{|c|}{ First assessment } & \multicolumn{7}{|c|}{ Second assessment } & \multirow{2}{*}{\multicolumn{2}{|c|}{$\begin{array}{l}\text { Agreement } \\
\text { between } \\
\text { physicians }\end{array}$}} \\
\hline & & \multirow[t]{2}{*}{$\mathbf{N}$ total } & \multicolumn{2}{|c|}{$\begin{array}{l}\text { Absent } \\
\text { NePC }\end{array}$} & \multicolumn{2}{|c|}{$\begin{array}{l}\text { Present } \\
\text { NePC }\end{array}$} & \multirow[t]{2}{*}{$p$-value } & \multirow[t]{2}{*}{$\boldsymbol{v}$} & \multirow[t]{2}{*}{$\mathbf{N}$ total } & \multicolumn{2}{|c|}{$\begin{array}{l}\text { Absent } \\
\text { NePC }\end{array}$} & \multicolumn{2}{|c|}{$\begin{array}{l}\text { Present } \\
\text { NePC }\end{array}$} & \multirow[t]{2}{*}{$p$-value } & \multirow[t]{2}{*}{$V$} & & \\
\hline & & & $\bar{n}$ & $\%$ & $\bar{n}$ & $\%$ & & & & $\bar{n}$ & $\%$ & n & $\%$ & & & $K$ & PA (\%) \\
\hline \multirow[t]{4}{*}{ Unpleasant } & Total & 290 & 57 & 5 & 170 & 10 & 0.528 & 0.075 & 290 & 58 & 5 & 169 & 11 & 0.275 & 0.107 & 0.225 & 85.4 \\
\hline & LBLP & 132 & 28 & 4 & 75 & 8 & 0.571 & 0.105 & 132 & 28 & 0 & 75 & 7 & 0.304 & 0.152 & 0.362 & 91.3 \\
\hline & NSAP & 50 & 17 & 6 & 23 & 9 & 0.738 & 0.053 & 50 & 18 & 6 & 22 & 23 & 0.130 & 0.239 & 0.133 & 87.2 \\
\hline & sPND & 108 & 12 & 8 & 72 & 13 & 0.838 & 0.065 & 108 & 12 & 17 & 72 & 13 & 0.855 & 0.061 & 0.155 & 79.8 \\
\hline \multirow[t]{4}{*}{ Painful } & Total & 291 & 58 & 3 & 170 & 8 & 0.517 & 0.076 & 290 & 58 & 0 & 169 & 7 & 0.114 & 0.138 & 0.435 & 93.0 \\
\hline & LBLP & 132 & 28 & 4 & 75 & 9 & 0.720 & 0.080 & 132 & 28 & 0 & 75 & 3 & 0.562 & 0.106 & 0.380 & 94.2 \\
\hline & NSAP & 51 & 18 & 0 & 23 & 13 & 0.111 & 0.249 & 50 & 18 & 0 & 22 & 14 & 0.103 & 0.258 & 0.640 & 95.0 \\
\hline & sPND & 108 & 12 & 8 & 72 & 8 & 0.919 & 0.045 & 108 & 12 & 0 & 72 & 8 & 0.299 & 0.113 & 0.381 & 90.5 \\
\hline
\end{tabular}

Notes: Classification for the existence of NePC is based on the physicians' assessment of the patient. $n$, the number of patients; \%, the percentage of positive answers (yes) on the questions; Sensation, Is there a sensation?; Unpleasant, Is the sensation unpleasant?; Painful, Is the sensation painful?; $p$-value, $p$ value for statistical significant difference between groups (outcome of chi-square test, $p \leq 0.05)$. Bold values are statistically significant $(p \leq 0.05)$.

Abbreviations: NePC, neuropathic pain component; LBLP, low back and leg pain; NSAP, neck shoulder arm pain; sPND, suspected peripheral nerve damage; $V$, value of Cramér's V; K, Kappa value; PA, percentage of agreement.

\section{Publish your work in this journal}

The Journal of Pain Research is an international, peer reviewed, open access, online journal that welcomes laboratory and clinical findings in the fields of pain research and the prevention and management of pain. Original research, reviews, symposium reports, hypothesis formation and commentaries are all considered for publication.
The manuscript management system is completely online and includes a very quick and fair peer-review system, which is all easy to use. Visit http://www.dovepress.com/testimonials.php to read real quotes from published authors. 